\section{Dose Calculation Accuracy of Radiotherapy Treatment Planning Systems in Out-of-Field Regions}

\author{
Farhood B. ${ }^{1}$, Ghorbani M. ${ }^{2 *}$
}

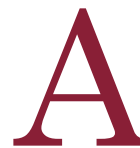

long with chemotherapy and surgery, radiotherapy remains as an important modality in tumor treatment, as it is used to treat approximately $50 \%$ of all patients with localized cancer [1-3]. However, the use of radiotherapy inevitably leads to exposing the organs/tissues that are entirely or partially excluded from the treatment volume [4]. Therefore, out-of-field regions receive dose values due to secondary radiation sources, including scattered radiation from collimators and beam modifiers, photon leakage through the treatment head of the linear accelerator (Linac), and internal patient radiation scattering [5]. In a study by Kase, et al. [6], it was found that the radiation scattering from patient is the main cause of dose near the edge of treatment field, while the leakage radiation has the main contribution at large distances from the edge of treatment field. Although dose value in out-of-field region is smaller than that in-field region, these doses can induce secondary malignancies with a long-latency period (particularly in radiosensitive tissue/organs) [7-8]. Furthermore, knowledge of the peripheral dose can be of very interest when considering radiation therapy for patients with pregnancy or patients with cardiac pacemaker. Therefore, accurate measurement of the peripheral dose to normal tissue outside the target volume is essential, to have an adequate clinical decision for patients with implanted electronic devices or pregnant patients as well as more accurate estimation of the radiation-induced secondary cancer risk.

Generally, it has been accepted that the dose calculation accuracy in out-of-field regions by treatment planning systems (TPSs) is poor. This can be found out by reviewing the specified protocols for quality assurance and commissioning of TPSs, which suggest an agreement criterion of up to $50 \%$ in the low dose/small dose gradient region of photon beams between the TPS calculations and experimental measurements [9-10]. There are several factors which can affect poor performance of TPSs in out-of-field regions, including the lack of TPS commissioning for out-of-field regions, the limitations of TPSs in modelling the dose contributions from contaminated electrons originated from the collimator assembly, flattening filter, and secondary scattered photons from the Linac's head [11-12].
${ }^{1}$ Department of Medical

Physics and Radiology,

Faculty of Paramedi-

cal Sciences, Kashan

University of Medical

Sciences, Kashan, Iran

${ }^{2}$ Biomedical Engineer-

ing and Medical Phys-

ics Department, Fac-

ulty of Medicine, Shahid

Beheshti University of

Medical Sciences, Teh-

ran, Iran

*Corresponding author: M. Ghorbani

Biomedical Engineering and Medical Physics Department, Faculty of Medicine, Shahid Beheshti University of Medical Sciences, Velenjak, Tehran, Iran

E-mail: mhdghorbani@ gmail.com

Received: 21 January 2018 Accepted: 28 March 2018 
There are several studies which have quantified the dose calculation accuracy of different TPSs in out-of-field regions [5, 12-16]. In a study, Huang, et al. [5] reported that Pinnacle TPS underestimates the out of field dose by an average of $50 \%$ for intensity modulated radiation therapy (IMRT) treatment plans and this underestimation is worsened with increasing distance from the edge of treatment field. Howell, et al. [12] stated that Eclipse TPS underestimated out of field doses by an average of 40\%. Bahreyni Toossi, et al. [13] revealed that TiGRT TPS generally underestimated out-of-field dose by an average of $39 \%$ and this underestimation increased for areas which are relatively close to the edge of treatment field. In another study, Bahreyni Toossi [14] investigated dose accuracy of TiGRT TPS for head and neck region and revealed it for most of the points, the difference between calculated and measured dose for outof-field regions are less than 40\%. Morever, their findings demonstrated TPS underestimated dose of the outside field which is mentioned compared to the corresponding measurements. Farhood, et al. [15] reported that TiGRT TPS underestimated the out-of-field dose for most points in physical wedged field and the confidence limit value for region was 55.24.

Consequently, underestimation of the dose was received by a radiosensitive organ using a TPS, so it leads to increase the probability of contracting another cancer to an underestimation of the risk of induction of second cancer. As it was stated by Kry, et al. [17], a 50\% variation in low dose value can enough so as to cause a remarkable difference in the second cancer risk. On the other hand, a severe underestimation of out-of-field dose can lead to a poor clinical decision-making for patients with implantable electronic devices or pregnant patients. Therefore Thus, an assessment of dose at out-of-field regions should not generally rely on TPS calculations. It menas for accurate evaluation of out-of-field dose values other dose reconstruction methods should be utilized to reveal accurate evaluation of it. These methods can include calculations by Monte Carlo simulations or other analytical models, measurements in a phantom, or other calculation methods [18].

\section{Conflict of Interest}

There is not any relationship that might lead to a conflict of interest

\section{References}

1. Ringborg U, Bergqvist D, Brorsson B, Cavallin-Stahl E, Ceberg J, Einhorn N, et al. The Swedish Council on Technology Assessment in Health Care (SBU) systematic overview of radiotherapy for cancer including a prospective survey of radiotherapy practice in Sweden 2001--summary and conclusions. Acta Oncol. 2003;42:357-65. doi.org/10.1080/02841860310010826. PubMed PMID: 14596499.

2. Delaney G, Jacob S, Featherstone $C$, Barton M. The role of radiotherapy in cancer treatment: estimating optimal utilization from a review of evidence-based clinical guidelines. Cancer. 2005;104:1129-37. doi.org/10.1002/cncr.21324. PubMed PMID: 16080176.

3. Begg AC, Stewart FA, Vens C. Strategies to improve radiotherapy with targeted drugs. Nat Rev Cancer. 2011;11:239-53. doi.org/10.1038/nrc3007. PubMed PMID: 21430696.

4. Bagheri H, Rabie Mahdavi S, Shekarchi B, Manouchehri F, Farhood B. Measurement of the contralateral breast photon and thermal neutron doses in breast cancer radiotherapy: a comparison between physical and dynamic wedges. Radiat Prot Dosimetry. 2018;178:7381. doi.org/10.1093/rpd/ncx076. PubMed PMID: 28591863. 
5. Huang JY, Followill DS, Wang XA, Kry SF. Accuracy and sources of error of out-of field dose calculations by a commercial treatment planning system for intensity-modulated radiation therapy treatments. J Appl Clin Med Phys. 2013;14:4139. doi.org/10.1120/jacmp. v14i2.4139. PubMed PMID: 23470942. PubMed PMCID: 5714363.

6. Kase KR, Svensson GK, Wolbarst AB, Marks MA. Measurements of dose from secondary radiation outside a treatment field. Int $J$ Radiat Oncol Biol Phys. 1983;9:1177-83. doi. org/10.1016/0360-3016(83)90177-3. PubMed PMID: 6409854.

7. Kaderka R, Schardt D, Durante M, Berger T, Ramm U, Licher J, et al. Out-of-field dose measurements in a water phantom using different radiotherapy modalities. Phys Med Biol. 2012;57:5059-74. doi.org/10.1088/0031-9155/57/16/5059. PubMed PMID: 22836598.

8. La Tessa C, Berger T, Kaderka R, Schardt D, Korner C, Ramm U, et al. Out-of-field dose studies with an anthropomorphic phantom: comparison of X-rays and particle therapy treatments. Radiother Oncol. 2012;105:133-8. doi.org/10.1016/j.radonc.2012.04.004. PubMed PMID: 22575675.

9. Andreo P, Cramb J, Fraass B, Ionescu-Farca F, Izewska J, Levin V, et al. Commissioning and quality assurance of computerized planning systems for radiation treatment of cancer. International Atomic Energy Agency technical report series. 2004;430.

10. Vatnitsky S. Specification and Acceptance Testing in Radiotherapy Treatment Planning Systems. Vienna: IAEA; 2007.

11. Mohammadi K, Hassani M, Ghorbani M, Farhood B, Knaup C. Evaluation of the accuracy of various dose calculation algorithms of a commercial treatment planning system in the presence of hip prosthesis and comparison with Monte Carlo. $J$ Cancer Res Ther. 2017;13:501-9. doi.org/10.4103/0973-1482.204903. PubMed PMID: 28862217.

12. Howell RM, Scarboro SB, Kry SF, Yaldo DZ. Accuracy of out-of-field dose calculations by a commercial treatment planning system. Phys Med Biol. 2010;55:6999-7008. doi. org/10.1088/0031-9155/55/23/S03. PubMed PMID: 21076191. PubMed PMCID: 3152254.

13. Bahreyni Toossi M, Sh S, Farhood B, Sh M, Davenport D. Assessment of accuracy of out-of-field dose calculations by TiGRT treatment planning system in radiotherapy. J Cancer Res Ther. 2016.

14. Bahreyni Toossi MT, Farhood B, Soleymanifard S. Evaluation of dose calculations accuracy of a commercial treatment planning system for the head and neck region in radiotherapy. Rep Pract Oncol Radiother. 2017;22:420-7. doi.org/10.1016/j.rpor.2017.06.001. PubMed PMID: 28855853. PubMed PMCID: 5565749.

15. Farhood B, Bahreyni Toossi MT, Soleymanifard S. Assessment of Dose Calculation Accuracy of TiGRT Treatment Planning System for Physical Wedged fields in Radiotherapy. Iranian Journal of Medical Physics. 2016;13:146-53.

16. Mahmoudi G, Farhood B, Shokrani P, Amouheidari A, Atarod M. Evaluation of the photon dose calculation accuracy in radiation therapy of malignant pleural mesothelioma. 2018.

17. Kry SF, Followill D, White RA, Stovall M, Kuban DA, Salehpour M. Uncertainty of calculated risk estimates for secondary malignancies after radiotherapy. Int $J$ Radiat Oncol Biol Phys. 2007;68:1265-71. doi.org/10.1016/j.jirobp.2007.04.014. PubMed PMID: 17637398.

18. Howell RM, Scarboro SB, Taddei PJ, Krishnan S, Kry SF, Newhauser WD. Methodology 
for determining doses to in-field, out-of-field and partially in-field organs for late effects studies in photon radiotherapy. Phys Med Biol. 2010;55:7009-23. doi.org/10.1088/00319155/55/23/S04. PubMed PMID: 21076193. PubMed PMCID: 3001332. 